\title{
A statistical comparison of the stochastic weather generators WGEN and SIMMETEO
}

\author{
Afshin Soltani ${ }^{1, *}$, Gerrit Hoogenboom ${ }^{2}$ \\ ${ }^{1}$ Department of Agronomy and Plant Breeding, Gorgan University of Agricultural Sciences, PO Box 386, Gorgan, Iran \\ ${ }^{2}$ Department of Biological and Agricultural Engineering, The University of Georgia, Griffin, Georgia 30223, USA
}

\begin{abstract}
Weather generators are frequently used to provide weather data when the length of historical weather data is inadequate or when future data are required. The main objective of this study was to evaluate the weather generators WGEN and SIMMETEO as implemented in the Decision Support System for Agrotechnology Transfer (DSSAT) for 5 Iranian locations with contrasting climates. The algorithms for generating weather data are the same in both programs, but they differ with respect to the methods used for parameter estimation. While WGEN requires daily weather data for parameter estimation, SIMMETEO uses monthly summaries. Therefore, the second objective of this study was to evaluate the effect of the parameter-estimation method on the quality of generated weather data. Extensive statistical evaluations, including $t-, F$ - and Kolmogorov-Smirnov tests, were conducted to analyze the differences between observed and generated weather data as well as between generated series. The results showed that the algorithms used to generate precipitation work well. For solar radiation, WGEN showed a poor and SIMMETEO a good performance. WGEN was successful in reproducing maximum and minimum temperatures, and SIMMETEO in reproducing minimum temperature. However, SIMMETEO showed a moderate performance for maximum temperature. SIMMETEO did not generate extreme temperatures well, but WGEN showed a good performance for generating the number of frost days and a moderate performance for the number of hot days. It can be concluded that, when daily weather data are available, WGEN should be preferred for generating weather data. However, when only monthly summaries are available or when resources are limited for preparation of daily weather data, SIMMETEO should be used. It was also found that series generated with identical parameters but different 'seeds' for initialization may be significantly different from each other. More research is, however, needed on this aspect of weather generators.
\end{abstract}

KEY WORDS: Weather generator $\cdot$ Stochastic model $\cdot$ Temperature $\cdot$ Precipitation $\cdot$ Solar radiation · DSSAT

Resale or republication not permitted without written consent of the publisher

\section{INTRODUCTION}

Weather data are required as input for decision support systems to help to address a wide range of problems in agricultural, ecological and hydrological studies (Pickering et al. 1994, Hoogenboom 2000, Jones \& Thornton 2000). The meteorological variables needed for most of these studies include daily precipitation, maximum and minimum temperature, and solar radiation. Generated daily weather data can be used in a variety of applications to complete or replace longterm series of historical data, especially if the data sets are of inadequate length or if they are erroneous (Hoogenboom 2000). Generated data are sometimes used to provide various combinations of weather realizations for risk-analysis studies (Mavromatis \& Hansen 2001), where the probability distribution of the simulated outcomes is important for understanding the system, or for decision-making (Thornton \& Hoogenboom 1994). Generated weather data can be used as input for hydrologic models for watershed planning, evaluation and design purposes (Richardson 1981) and for analysis of water resources (Hayhoe 2000). They can also be used in various types of agricultural man- 
agement models to assess the risks associated with different alternatives (Larsen \& Pense 1982, Hayhoe 1998, O'Leary \& Connor 1998). In a real-time mode, generated data can be used as future sequences in crop-simulation models for yield forecasting (Thornton et al. 1997, Bannayan \& Crout 1999, Georgiev \& Hoogenboom 1999). In recent years, weather generators have been used extensively in climate change and variability studies to determine the potential impact on agricultural production (Mearns et al. 1996, Riha et al. 1996, Semenov \& Barrow 1998). The parameters of these models can be manipulated to yield synthetic time series exhibiting different types and magnitudes of climate change or variability (Wilks 1992).

Several weather generators have been developed. These include WGEN (Richardson \& Wright 1984), SIMMETEO (Geng \& Auburn 1986, Geng et al. 1986, 1988), LARS-WG (Semenov \& Barrow 1997, Semenov et al. 1998), TAMSIM (McCaskill 1990), MARKSIM (Jones \& Thornton 2000) and others (e.g. Larson \& Pense 1982, Guenni et al. 1991, Hayhoe 2000).

In this study, we used the 2 weather generators WGEN and SIMMETEO that have been implemented in WeatherMan (Pickering et al. 1994). The main difference between SIMMETEO and WGEN is that the generation parameters for SIMMETEO can be estimated from monthly climatic summaries, while WGEN requires daily data for estimating the input parameters. Using monthly climatic summaries for parameter estimation in SIMMETEO compared to using daily weather data for parameter estimation in WGEN is an important advantage, because reliable monthly values of weather variables are readily accessible from many sources, such as the National Weather Services in the USA and other national weather services. Preparation of complete sets of daily weather data, as required for WGEN, in a suitable input format and with necessary attention to quality control is time consuming and costly.

By definition, weather generators will generate the same (in terms of statistical characteristics) data as their original inputs. However, one of the main concerns of using stochastic generation of weather variables is that they may fail to adequately represent the statistical properties of observed weather series (Hayhoe 1998, 2000), particularly with respect to extremes and interannual variability. Therefore, the output of a weather generator should be tested to ensure its representation for a given climate and intended application, because the performance of the generators may vary considerably for different climates and/or applications (Semenov et al. 1998, Elliot \& Arnold 2001). In addition, the evaluation and comparison of weather generators is important because the potential and limitations of the generators are shown. Developers of weather generators can then use this information for improvement of the generators.

WGEN has been evaluated in a number of studies (e.g. Meinke et al. 1995, Semenov et al. 1998, Puche \& Silva 2001, Warnock \& Puche 2001, Hartkamp et al. 2003), but literature concerning SIMMETEO is rare (Sentelhas et al. 2001, Hartkamp et al. 2003). So far there have been no studies that have evaluated WGEN or SIMMETEO for climates in Iran, except for one study by Soltani et al. (2000), who evaluated WGEN in Tabriz (NW Iran, with a cold semi-arid climate) with parameters determined from a very limited set of input data (3 to $10 \mathrm{yr}$ ). Iran has arid and semi-arid climates and the occurrence of precipitation is unreliable, with a coefficient of variation as high as $70 \%$. Humid and sub-humid climates are found in the highlands and on the coast of the Caspian Sea. Precipitation generally occurs from October to May. Temperature regimes vary from cold to warm in combination with different precipitation regimes. In addition, no studies have been conducted that compared series generated using the same generator. There has been no report that has compared the quality of generated weather data when the generation parameters are estimated from daily data versus monthly summaries. A comparison of WGEN and SIMMETEO will show any effects of the differences in parameter-estimation method on the generated weather series because both generators use the same generation method. Sentelhas et al. (2001) and Hartkamp et al. (2003) compared WGEN and SIMMETEO for the climate conditions of the Brazilian tropics and sub-tropics and the Mexican sub-tropics, respectively. However, they neither related the quality of generated weather to the parameter-estimation method nor compared parameter estimates from daily data versus monthly summaries.

There were 3 specific objectives of this research. The first objective was the evaluation of the 2 generators for 5 locations across Iran representing different climates. The second objective was to evaluate the impact of the parameter-estimation method, i.e. from daily weather data versus monthly summaries, on the quality of the generated weather data. The third objective was to compare different weather series generated by the same generator, using different 'seeds' to initialize the generation, but with identical generation parameters.

\section{METHODS AND DATA}

\subsection{Weather generators}

The weather generators used in this study were adaptations of WGEN (Richardson \& Wright 1984) and SIMMETEO (Geng et al. 1986, 1988) as implemented 
in WeatherMan (Pickering et al. 1994). Other versions and modifications of these generators are also available, such as WXGEN (Hayhoe 1998, Hayhoe \& Stewart 1996) and Simeto (S. Geng pers. comm.). WGEN and SIMMETEO are well-known and widely used stochastic weather generators that require a number of local parameters as input to be able to generate a weather series for a specific site. These generators have also been incorporated in the weather data manager WeatherMan (Pickering et al. 1994), an application program that is part of the Decision Support System for Agrotechnology Transfer (DSSAT) software (Tsuji et al. 1994, Hoogenboom et al. 1999). DSSAT is a suite of crop models and computer programs integrated into a single software package in order to facilitate the application of crop-simulation models in research and decision-making.

The WGEN generator calculates daily values for precipitation, maximum and minimum air temperatures and solar radiation for an $n$ yr period at a given location. Precipitation is generated independently for a given day. Maximum temperature and solar radiation are then generated depending on whether the generated day is wet or dry. The precipitation component of WGEN is a Markov-chain-gamma-distribution model. The occurrence of wet or dry days is generated with a first-order Markov-chain model in which the probability of rain on a given day is conditioned on whether the previous day was wet or dry. When a wet day is generated, the 2-parameter gamma distribution is used to generate the precipitation amount. Daily maximum temperature and solar radiation are sampled from normal distributions parameterized separately for wet and dry days, with sampling conditioned on precipitation occurrence. Distributions of solar radiation are truncated at 16 and $85 \%$ of extraterrestrial irradiance. Minimum temperature is sampled from a normal distribution independently of precipitation occurrence. Lag1 auto- and cross-correlations among maximum and minimum temperatures and solar radiation are maintained by sampling random normal deviates from a trivariate autoregressive model. Constant correlation coefficients, derived from an analysis of 31 stations in the continental US, are used for all locations and seasons. The final values of the 3 variables are determined by adding the seasonal means and standard deviations to the generated residual elements. The original WGEN derives daily means and standard deviations for maximum and minimum temperatures and solar radiation from an annual cosine function. Specific details can be found in Richardson (1981), Richardson \& Wright (1984), Semenov et al. (1998) and Mavromatis \& Hansen (2001). The major adaptations of WGEN relate to how WeatherMan handles input parameters. All parameters are estimated on a calendar-month basis. Daily values are computed internally, using linear interpolation. WeatherMan replaces coefficients of variation $(\mathrm{CV})$ with standard deviations to avoid instability problems when temperatures approach $0^{\circ} \mathrm{C}$ (Mavromatis \& Hansen 2001).

The SIMMETEO generator of WeatherMan is the same as in the WGEN generator, but uses different input data. The modified SIMMETEO model uses monthly climatic means of the number of wet days, precipitation, solar radiation, maximum temperature and minimum temperature, and regression equations to compute conditional means, standard deviations and precipitation parameters (Geng et al. 1986, 1988, Pickering et al. 1994). Transitional probabilities for each month, i.e. the probability of a wet day (PW) and the probability of a wet day following a dry day (PDW), are calculated from monthly total precipitation (PTOT) and the number of wet days (WD) (Table 1, Eqs. 1,2 \& $3)$. The 2 parameters of the gamma-distribution function ( $\alpha$ and $b)$ are directly related to the average amount of precipitation per wet day (PWET) (Table 1, Eqs. 4 \& 5).

Monthly means of solar radiation and maximum temperature for dry and wet days and their standard deviations are also required for weather generation. All of these parameters $(\mathrm{Y})$ are estimated for each month $(\mathrm{M}$, 1-12) using first-order Fourier series that require 3 coefficients. The coefficients are meaningful: AV is the annual average of $Y$, AMP is half of the difference between the maximum and minimum of $\mathrm{Y}$ (amplitude), and ANG is the time (month number) at which $\mathrm{Y}$ reaches its maximum (phase angle) (Table 1, Eqs. 6 \& 7). Annual average solar radiation for dry (SRDAV) and wet (SRWAV) days are computed from the solar radiation difference (SDIF), which is related to latitude (LAT) and annual mean solar radiation for all days (SAVG), and PW (Table 1, Eqs. 8 \& 10). The coefficients AMP and ANG are calculated by fitting the Fourier equation to monthly mean solar radiation and are used for SRDAV and SRWAV. Standard deviations of solar radiation on dry $\left(R_{\mathrm{D}}\right)$ and wet $\left(R_{\mathrm{W}}\right)$ days are calculated from their means and coefficients of variation $(C V)$. Annual average CV of 0.24 for $R_{\mathrm{D}}$ and 0.48 for $R_{\mathrm{W}}$ and amplitudes of 0.08 for $R_{\mathrm{D}}$ and 0.13 for $R_{\mathrm{W}}$ are considered for the Fourier equation that describes the $\mathrm{CV}$ of $R_{\mathrm{D}}$ and $R_{\mathrm{W}}$. The coefficient ANG derived from monthly mean solar radiation is used for calculating the $\mathrm{CV}$ of $R_{\mathrm{D}}$ and $R_{\mathrm{W}}$. Similarly, mean annual maximum temperatures for dry (TXDAV) and wet (TXWAV) days are calculated from the temperature difference (TDIF), which is related to PW, PDW and annual average maximum temperature (TXAV) (Table 1, Eqs. 11,12 \& 13). The other 2 coefficients, AMP and ANG, are computed from the monthly mean maximum temperature. For each month, standard deviations of the maximum tem- 
Table 1. Equations used in SIMMETEO for parameter estimation from monthly summaries (from source codes of WeatherMan; Pickering et al. 1994). PWET = average amount of precipitation per wet day $\left(\mathrm{mm} \mathrm{d}^{-1}\right)$; PTOT $=$ monthly total precipitation $(\mathrm{mm}) ; \mathrm{PW}=$ probability of a wet day; $\mathrm{WD}=$ number of wet days per month; NDAY = number of days per month; PDW = probability of a wet day following a dry day; BETA = a parameter of the gamma-distribution function; ALPHA = a parameter of the gamma-distribution function; $\mathrm{Y}=$ variable described by Fourier series; $\mathrm{AV}=$ annual average of $\mathrm{Y} ; \mathrm{AMP}=$ amplitude of $\mathrm{Y} ; \mathrm{ANG}=$ phase angle for $\mathrm{Y} ; \mathrm{M}=$ month number $(1-12) ; \mathrm{SDIF}=$ solar radiation difference; $\mathrm{LAT}=$ latitude of location; $\mathrm{SAVG}=$ annual average solar radiation; SRDAV = annual average solar radiation on dry days; SRWAV = annual average solar radiation on wet days; TDIF = temperature difference; TXDAV = mean annual maximum temperature for dry days; TXWAV = mean annual maximum temperature for wet days; TXAV = mean annual maximum temperature for all days; TXDSD = standard deviation of maximum temperature for dry days in a given month; TXWSD = standard deviation of maximum temperature for wet days in a given month; TXDMN = mean monthly maximum temperature for dry days in a given month; TXWMN = mean monthly maximum temperature for wet days in a given month; TNSD = standard deviation of minimum temperature in a given month; TNMN = mean monthly minimum temperature in a given month. In Eq. (8), 0.04189 is used to convert Longeleys to $\mathrm{MJ} \mathrm{m}^{-2} \mathrm{~d}^{-1}$; in Eq. (11), 5/9 is used to convert ${ }^{\circ} \mathrm{F}$ to ${ }^{\circ} \mathrm{C}$

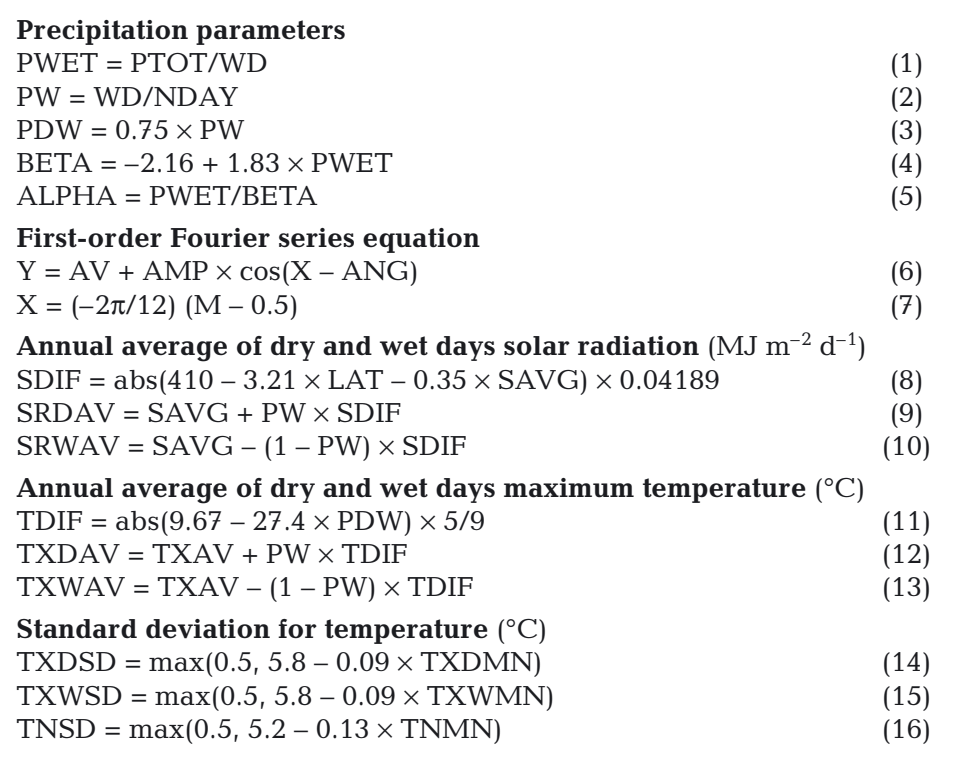

perature on dry and wet days and minimum temperature are calculated from their monthly means (Table 1, Eqs. 14, 15 \& 16).

\subsection{Historical weather data sets}

Five climate stations with long-term and reliable daily weather data were selected for the study to represent a large geographical area and several climatic zones in Iran. The selected sites are Gorgan, Kermanshah, Isfahan, Ahwaz and Shiraz, and the important climatic characteristics for these locations are presented in Table 2.
For each location, 30 yr (1966-1995) of daily data for precipitation and maximum and minimum temperatures were available. Solar-radiation data were calculated from sunshine hours and extraterrestrial radiation. For days without sunshine-hour data (about 3 to $9 \%$ of the data), solar radiation was calculated based on locally determined relationships between precipitation, temperature and solar radiation. These relationships are similar to those presented by Hunt et al. (1998) but with different coefficients (A. Soltani unpubl. data). With estimated solar-radiation data, a complete data set of $30 \mathrm{yr}$ of daily precipitation, maximum and minimum temperatures and solar radiation data was available for each location.

\subsection{Analysis}

The input parameters for the 2 weather generators were obtained from either the daily (WGEN) or the monthly (SIMMETEO) summaries of $30 \mathrm{yr}$ of daily weather data. For each location, three 30 yr daily time series were generated with WGEN and SIMMETEO using different 'seed numbers' to initialize each generation. Each 30 yr series was taken as an independent replication and used to test for significant differences between series.

For each site, monthly means and variances of the number of wet days (WD), precipitation $(P)$, solar radiation $(R)$, maximum temperature $\left(T_{\mathrm{X}}\right)$, minimum temperature $\left(T_{\mathrm{N}}\right)$, number of days with a maximum temperature greater than $35^{\circ} \mathrm{C}\left(T_{\mathrm{X}}>\right.$ 35 , hot day) and number of days with a minimum temperature less than $0^{\circ} \mathrm{C}\left(T_{\mathrm{N}}<\right.$ 0 , frost day) were computed for the historical data as well as for the 2 sets of generated data. Statistical analyses were conducted using $t$ - and $F$-tests to determine the differences between generated series $(g-g)$ and differences between observed and generated series $(\mathrm{o}-\mathrm{g})$ with respect to mean and variance.

Cumulative distribution functions (CDFs) were calculated for daily data for each month separately and compared by month. The CDFs were then compared and tested for significant differences using the Kolmogorov-Smirnov test $(\mathrm{K}-\mathrm{S})$.

All tests were conducted using a 0.01 level of significance. The statistical comparisons were conducted with the Statistical Analysis System (SAS Institute 
Table 2. Climatic characteristics of the selected locations. Temperature amplitude is half of the difference between the temperature of the warmest month minus the temperature of the coldest month

\begin{tabular}{|lccccc|}
\hline Characteristic & Gorgan & Kermanshah & Isfahan & Ahwaz & Shiraz \\
\hline Latitude $\left({ }^{\circ} \mathrm{N}\right)$ & 36.85 & 34.32 & 32.67 & 31.33 & 29.55 \\
Longitude $\left({ }^{\circ} \mathrm{E}\right)$ & 54.27 & 47.12 & 51.87 & 48.67 & 52.60 \\
Elevation $(\mathrm{m})$ & 13 & 1322 & 1600 & 22 & 1488 \\
Mean temperature $\left({ }^{\circ} \mathrm{C}\right)$ & 17.6 & 14.0 & 16.2 & 24.9 & 17.5 \\
Temperature amplitude $\left({ }^{\circ} \mathrm{C}\right)$ & 10.0 & 12.7 & 12.9 & 12.5 & 11.5 \\
Mean solar radiation, $R\left(\mathrm{MJ} \mathrm{m}^{-2} \mathrm{~d}^{-1}\right)$ & 15.7 & 18.7 & 20.2 & 19.7 & 21.0 \\
Mean max. temperature, $T_{\mathrm{X}}\left({ }^{\circ} \mathrm{C}\right)$ & 22.7 & 22.2 & 23.0 & 32.6 & 25.6 \\
Mean min. temperature, $T_{\mathrm{N}}\left({ }^{\circ} \mathrm{C}\right)$ & 12.6 & 5.8 & 9.4 & 17.3 & 9.5 \\
Total precipitation $(\mathrm{mm})$ & 607 & 487 & Cold & Temperate & Cold \\
Climate regime & Temperate & Cold & arid & warm desert & semi-arid \\
& sub-humid & sub-humid & & & \\
\end{tabular}

1989). For each location there were approximately $1000 t$-tests, $1000 \mathrm{~F}$-test and $1000 \mathrm{~K}$-S tests (i.e. $3 \mathrm{~g}-\mathrm{g}$ $+3 \mathrm{o}-\mathrm{g}=6$ comparisons $\times 7$ variables $\times 12$ months $\times 2$ weather generators $[6 \times 7 \times 12 \times 2=1008])$. For the $t$-, $F$ - and $\mathrm{K}-\mathrm{S}$ tests, the total number of tests $(N)$, number of tests where a significant difference was detected $\left(N^{*}\right)$ and percentage of tests that were rejected $(=$ $N^{*} / N \times 100$ ) were determined.

\section{RESULTS AND DISCUSSION}

\subsection{Precipitation}

The statistics for precipitation need to be analyzed from 2 perspectives, i.e. the occurrence and the amount of precipitation. A proper description of the occurrence of wet days for each season is important, because the generation of radiation and maximum temperature by WGEN and SIMMETEO is conditioned on the occurrence of wet or dry days (Richardson \& Wright 1984, Mavromatis \& Hansen 2001). The monthly mean number of wet days generated with either WGEN or SIMMETEO was not significantly different from the monthly mean number of wet days calculated from observed data using the $t$-test for the selected sites (Table 3). Similar results were obtained for monthly precipitation totals, with no significant difference except for the WGEN generated data in Ahwaz, where $3 \%$ of the $t$-tests were rejected. This is contrary to the findings of Wallis \& Griffiths (1995), who reported that $65 \%$ and $11 \%$ of the $t$-tests for comparing monthly means of the number of wet days and total precipitation were rejected for 5 strategically located stations in Texas, USA.

When comparing variances of wet days using the $F$ test, the statistics were somewhat greater (Table 4). Across locations, 7 and $10 \%$ of $F$-tests for the number of wet days and 27 and $21 \%$ of $F$-tests for precipitation amount fell in the rejection region for WGEN and SIMMETEO, respectively (Table 4). The fraction of significant $F$-tests for the number of wet days and precipitation amount reported by Wallis \& Griffiths (1995) and Hayhoe \& Stewart (1996) were similar to those found for WGEN and SIMMETEO in this study.

When significant differences were detected between variances (for precipitation and other variables), the data generated by both generators had consistently lower standard deviations (variation) than the observed data, as presented in Table 5 for Gorgan and Kermanshah. This is a major problem with many weather generators (Wilks \& Wilby 1999) and is in agreement with the findings of Hayhoe \& Stewart (1996), Semenov et al. (1998) and Mavromatis \& Hansen (2001) for different types of climates. Mavromatis \& Hansen (2001), for example, demonstrated the need for some form of low-frequency variability correction in stochastic weather generators for applications in which reproducing the observed interannual variability is important.

WGEN and SIMMETEO were both equally successful in reproducing the length of wet periods (Fig. 1). Similar results were found for the length of dry periods (data not shown). The generators also did a good job in generating the number of heavy precipitation events at the selected locations (Fig. 2). There was no significant difference between the observed and generated number of heavy precipitation events.

As stated previously, WGEN and SIMMETEO include a first-order Markov chain to generate the occurrence of wet or dry days. Our results showed that this approach worked well for the climate conditions that were included in this study and were consistent with findings of others (Larsen \& Pense 1982, Richardson \& Wright 1984, Geng et al. 1986, Wilks 1999, Sentelhas et al. 2001, Hartkamp et al. 2003). However, Schubert (1994), Wallis \& Griffiths (1995), Semenov et al. (1998), Hayhoe (2000), Puche \& Silva (2001) and 
Table 3. Percentage of $t$-tests rejected when comparing the monthly means of observed vs generated data (o-g) and generated vs generated data $(\mathrm{g}-\mathrm{g}) . T_{\mathrm{X}}>35$ : number of days with a maximum temperature $>35^{\circ} \mathrm{C}_{i} T_{\mathrm{N}}<0$ : number of days with a minimum temperature $<0^{\circ} \mathrm{C}$. Weather variables: wet days (WD), precipitation $(P)$, solar radiation $(R)$, maximum temperature $\left(T_{\mathrm{X}}\right)$, minimum temperature $\left(T_{\mathrm{N}}\right)$, the number of days with a maximum temperature $>35^{\circ} \mathrm{C}\left(T_{\mathrm{X}}>35\right)$ and number of days with a minimum temperature $<0^{\circ} \mathrm{C}\left(T_{\mathrm{N}}<0\right)$

\begin{tabular}{|c|c|c|c|c|c|c|c|c|}
\hline & & WD & $P$ & $R$ & $T_{\mathrm{X}}$ & $T_{\mathrm{N}}$ & $T_{\mathrm{X}}>35$ & $T_{\mathrm{N}}<0$ \\
\hline \multicolumn{9}{|l|}{ Gorgan } \\
\hline \multirow[t]{2}{*}{ WGEN } & $0-g$ & 0.0 & 0.0 & 52.8 & 0.0 & 0.0 & 4.2 & 0.0 \\
\hline & $g-g$ & 0.0 & 11.1 & 0.0 & 0.0 & 0.0 & 0.0 & 0.0 \\
\hline \multirow[t]{2}{*}{ SIMMETEO } & $0-g$ & 0.0 & 0.0 & 30.6 & 16.7 & 3.0 & 41.7 & 61.1 \\
\hline & $g-g$ & 0.0 & 8.3 & 2.8 & 0.0 & 0.0 & 0.0 & 0.0 \\
\hline \multicolumn{9}{|l|}{ Kermanshah } \\
\hline \multirow[t]{2}{*}{ WGEN } & $0-g$ & 0.0 & 0.0 & 55.6 & 11.1 & 3.0 & 61.1 & 12.0 \\
\hline & $g-g$ & 0.0 & 0.0 & 2.8 & 2.8 & 0.0 & 0.0 & 3.8 \\
\hline \multirow[t]{2}{*}{ SIMMETEO } & $0-g$ & 0.0 & 0.0 & 2.8 & 36.1 & 8.0 & 66.7 & 29.6 \\
\hline & $g-g$ & 5.6 & 0.0 & 0.0 & 0.0 & 0.00 & 0.0 & 0.0 \\
\hline \multicolumn{9}{|l|}{ Isfahan } \\
\hline \multirow[t]{2}{*}{ WGEN } & $\mathrm{o}-\mathrm{g}$ & 0.0 & 0.0 & 61.1 & 2.8 & 5.0 & 20.0 & 0.0 \\
\hline & $g-g$ & 0.0 & 2.8 & 2.8 & 0.0 & 0.0 & 0.0 & 0.0 \\
\hline \multirow[t]{2}{*}{ SIMMETEO } & $0-g$ & 0.0 & 0.0 & 13.9 & 36.1 & 5.0 & 56.3 & 27.3 \\
\hline & $g-g$ & 0.0 & 0.0 & 0.0 & 0.0 & 0.0 & 0.0 & 0.0 \\
\hline \multicolumn{9}{|l|}{ Ahwaz } \\
\hline \multirow[t]{2}{*}{ WGEN } & $0-g$ & 0.0 & 2.8 & 47.2 & 8.0 & 0.0 & 11.1 & 0.0 \\
\hline & $g-g$ & 3.0 & 3.0 & 5.6 & 0.0 & 0.0 & 0.0 & 0.0 \\
\hline \multirow[t]{2}{*}{ SIMMETEO } & $0-9$ & 0.0 & 0.0 & 25.0 & 39.0 & 0.0 & 18.5 & 33.0 \\
\hline & $g-g$ & 0.0 & 3.3 & 5.6 & 0.0 & 0.0 & 0.0 & 0.0 \\
\hline \multicolumn{9}{|l|}{ Shiraz } \\
\hline \multirow[t]{2}{*}{ WGEN } & $0-g$ & 0.0 & 0.0 & 66.7 & 3.0 & 0.0 & 30.0 & 0.0 \\
\hline & $g-g$ & 3.0 & 0.0 & 2.8 & 3.0 & 0.0 & 4.8 & 0.0 \\
\hline \multirow[t]{2}{*}{ SIMMETEO } & $0-g$ & 0.0 & 0.0 & 2.8 & 28.0 & 3.0 & 50.0 & 33.3 \\
\hline & $g-g$ & 2.8 & 0.0 & 0.0 & 0.0 & 0.0 & 0.0 & 0.0 \\
\hline \multicolumn{9}{|c|}{ Across locations } \\
\hline \multirow[t]{2}{*}{ WGEN } & $0-g$ & 0.0 & 0.6 & 56.7 & 5.0 & 1.6 & 25.3 & 2.4 \\
\hline & $g-g$ & 1.2 & 3.4 & 2.8 & 1.2 & 0.0 & 1.0 & 0.0 \\
\hline \multirow[t]{2}{*}{ SIMMETEO } & $0-g$ & 0.0 & 0.0 & 15.0 & 31.2 & 3.8 & 46.6 & 36.9 \\
\hline & $g-g$ & 1.7 & 2.3 & 1.7 & 0.0 & 0.0 & 0.0 & 0.0 \\
\hline
\end{tabular}
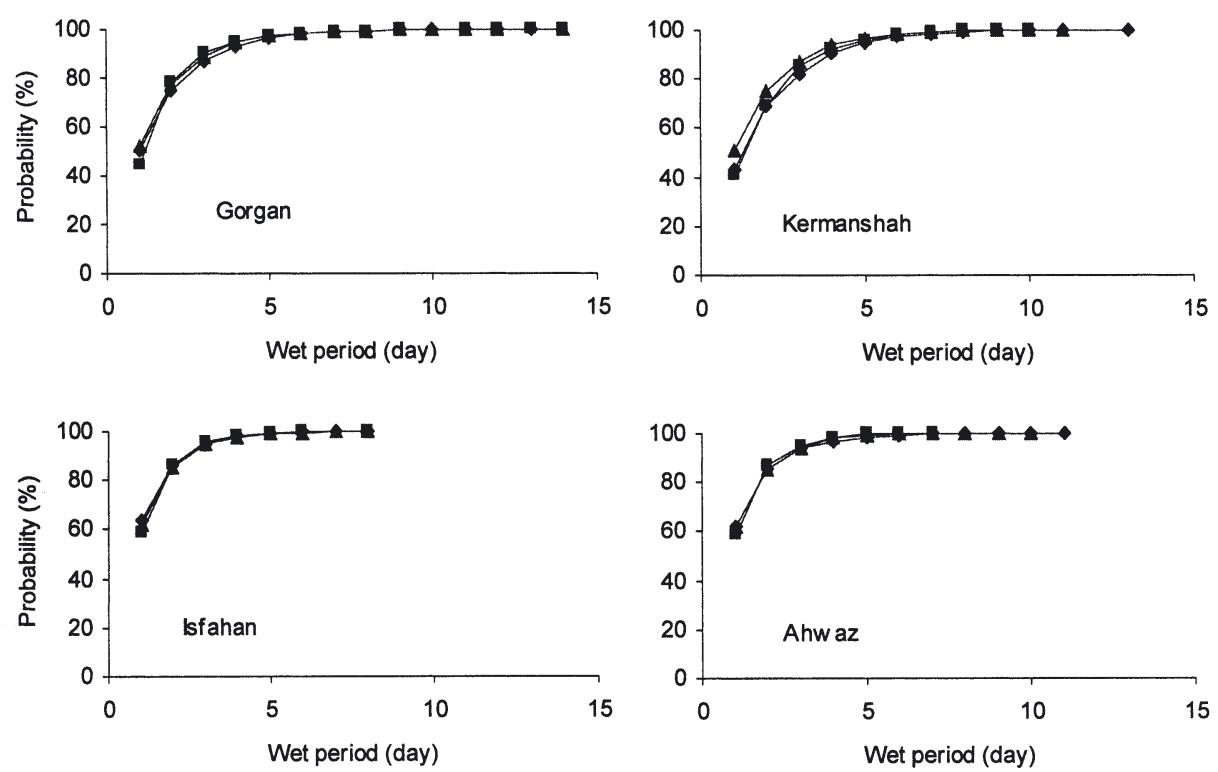
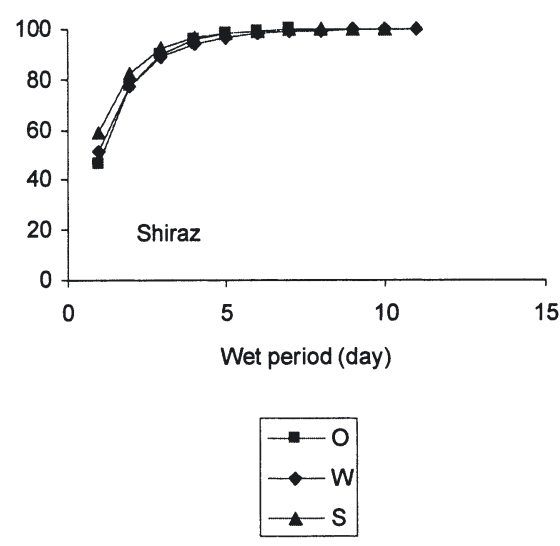

Fig. 1. Duration of wet periods for observed (O) and WGEN (W)and SIMMETEO (S)-generated precipitation data 
Table 4. Percentage of $F$-tests rejected when comparing variances of observed vs generated data (o-g) and generated vs generated data $(\mathrm{g}-\mathrm{g})$. See Table 3 for definitions

\begin{tabular}{|c|c|c|c|c|c|c|c|c|}
\hline & & WD & $P$ & $R$ & $T_{\mathrm{X}}$ & $T_{\mathrm{N}}$ & $T_{\mathrm{X}}>35$ & $T_{\mathrm{N}}<0$ \\
\hline \multicolumn{9}{|l|}{ Gorgan } \\
\hline \multirow[t]{2}{*}{ WGEN } & $0-g$ & 5.6 & 13.9 & 22.9 & 16.7 & 11.0 & 12.5 & 12.5 \\
\hline & $g-g$ & 0.0 & 8.3 & 0.0 & 2.8 & 3.0 & 8.7 & 23.5 \\
\hline \multirow[t]{2}{*}{ SIMMETEO } & $0-g$ & 2.8 & 2.8 & 0.0 & 8.3 & 5.0 & 16.7 & 5.6 \\
\hline & $g-g$ & 2.8 & 11.1 & 2.8 & 0.0 & 0.0 & 0.0 & 11.1 \\
\hline \multicolumn{9}{|l|}{ Kermanshah } \\
\hline \multirow[t]{2}{*}{ WGEN } & $0-g$ & 8.3 & 33.3 & 55.6 & 16.7 & 0.0 & 16.7 & 28.0 \\
\hline & $g-g$ & 11.1 & 27.8 & 2.8 & 0.0 & 0.0 & 16.7 & 15.4 \\
\hline \multirow[t]{2}{*}{ SIMMETEO } & $0-g$ & 19.4 & 25.0 & 5.6 & 22.2 & 0.0 & 11.1 & 29.6 \\
\hline & $g-g$ & 13.9 & 13.9 & 0.0 & 0.0 & 0.0 & 5.6 & 10.0 \\
\hline \multicolumn{9}{|l|}{ Isfahan } \\
\hline \multirow[t]{2}{*}{ WGEN } & $0-g$ & 2.8 & 33.3 & 44.4 & 17.0 & 5.0 & 60.0 & 5.0 \\
\hline & $g-g$ & 2.8 & 27.8 & 8.3 & 0.0 & 3.0 & 0.0 & 14.3 \\
\hline \multirow[t]{2}{*}{ SIMMETEO } & $\mathrm{o}-\mathrm{g}$ & 8.3 & 30.6 & 0.0 & 5.0 & 3.0 & 56.3 & 13.6 \\
\hline & $g-g$ & 8.3 & 19.4 & 0.0 & 0.0 & 0.0 & 0.0 & 8.7 \\
\hline \multicolumn{9}{|l|}{ Ahwaz } \\
\hline \multirow[t]{2}{*}{ WGEN } & $\mathrm{o}-\mathrm{g}$ & 5.6 & 27.8 & 52.8 & 19.0 & 5.0 & 25.9 & 35.7 \\
\hline & $g-g$ & 9.1 & 19.4 & 0.0 & 0.0 & 0.0 & 11.1 & 28.6 \\
\hline \multirow[t]{2}{*}{ SIMMETEO } & $\mathrm{o}-\mathrm{g}$ & 8.3 & 16.7 & 8.3 & 36.0 & 22.0 & 37.0 & 66.7 \\
\hline & $g-g$ & 3.3 & 33.3 & 0.0 & 0.0 & 3.0 & 16.7 & 20.0 \\
\hline \multicolumn{9}{|l|}{ Shiraz } \\
\hline \multirow[t]{2}{*}{ WGEN } & $\mathrm{o}-\mathrm{g}$ & 13.9 & 27.8 & 41.7 & 30.0 & 14.0 & 30.0 & 0.0 \\
\hline & $g-g$ & 18.2 & 30.6 & 0.0 & 0.0 & 0.0 & 0.0 & 0.0 \\
\hline \multirow[t]{2}{*}{ SIMMETEO } & $0-9$ & 11.1 & 30.6 & 0.0 & 3.0 & 14.0 & 35.0 & 19.0 \\
\hline & $g-g$ & 11.1 & 27.8 & 2.8 & 3.0 & 3.0 & 14.3 & 9.5 \\
\hline \multicolumn{9}{|c|}{ Across locations } \\
\hline \multirow[t]{2}{*}{ WGEN } & $\mathrm{o}-\mathrm{g}$ & 7.2 & 27.2 & 43.5 & 19.9 & 7.0 & 29.0 & 16.2 \\
\hline & $g-g$ & 8.2 & 22.8 & 2.2 & 0.6 & 1.2 & 7.3 & 16.4 \\
\hline \multirow[t]{2}{*}{ SIMMETEO } & $0-9$ & 10.0 & 21.1 & 2.8 & 14.9 & 8.8 & 31.2 & 26.9 \\
\hline & $g-g$ & 7.9 & 21.1 & 1.1 & 0.6 & 1.2 & 7.3 & 11.9 \\
\hline
\end{tabular}

Warnock \& Puche (2001) reported that the use of a first-order Markov chain could be a source of discrepancy between generated and observed data. Wilks (1999) found that a simple first-order Markov chain dependence was generally appropriate for central and eastern locations, but was inadequate for western locations in the USA. Jones \& Thornton (1997) recommended the use of a second- or higher-order Markov chain for sites that are not located in temperate regions. However, for sub-tropical climates, parameters for higher-order Markov chains are more difficult to obtain, usually less reliable and more sensitive to errors in estimating the occurrence of wet days (Hartkamp et al. 2003). Hartkamp et al. (2003) showed that MARKSIM, a generator that uses a third-order Markov chain, produced long chains of wet days that were not found in the observed data of 9 stations located in northwest Mexico.

WGEN and SIMMETEO use a gamma-distribution function to determine the precipitation amount when a wet day is generated. Our results showed that this approach also worked well in the selected locations of the study. However, some other researchers have obtained better results using other distribution functions. Alternate distributions that have been recommended to replace the gamma distribution used in

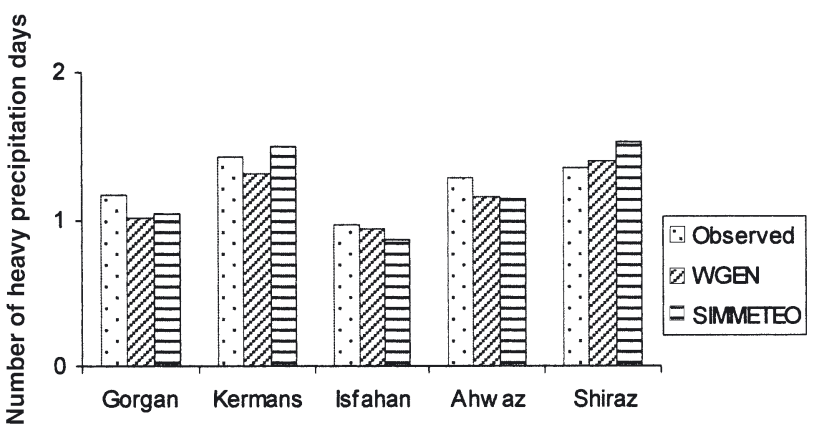

Fig. 2. Observed and WGEN- and SIMMETEO-generated number of days with heavy precipitation per year at selected locations. A heavy precipitation day was defined as a day with precipitation $>40 \mathrm{~mm}$ for Gorgan and $>30 \mathrm{~mm}$ for other locations 
WGEN and SIMMETEO are the semi-empirical distribution (Semenov et al. 1998) and distribution mixed exponential (Hansen \& Mavromatis 2001).
Parameter estimates for SIMMETEO for precipitation, calculated from the monthly number of wet days and precipitation amounts, were close to the parameter

Table 5. Observed and WGEN (W)- and SIMMETEO (S)-generated (1 of 3 series) standard deviations for different weather variables at Gorgan and Kermanshah. ${ }^{*} \mathrm{p}=0.01$. See Table 3 for definitions

\begin{tabular}{|c|c|c|c|c|c|c|c|c|c|c|c|c|}
\hline \multirow[b]{2}{*}{ Month } & \multicolumn{3}{|c|}{$P$} & \multicolumn{3}{|c|}{$R$} & \multicolumn{3}{|c|}{$T_{\mathrm{X}}$} & \multicolumn{3}{|c|}{$T_{\mathrm{N}}$} \\
\hline & Obs. & W & $\mathrm{S}$ & Obs. & W & $\mathrm{S}$ & Obs. & W & $\mathrm{S}$ & Obs. & W & $\mathrm{S}$ \\
\hline \multicolumn{13}{|l|}{ Gorgan } \\
\hline Jan & 25.3 & 28.4 & 37.4 & 0.86 & $0.42^{*}$ & 0.70 & 2.87 & $1.69^{*}$ & 1.97 & 1.83 & 1.25 & 2.06 \\
\hline Feb & 25.6 & 27.4 & 33.5 & 0.81 & 0.71 & 1.08 & 2.36 & 1.64 & 1.86 & 1.85 & 1.19 & 1.70 \\
\hline Mar & 26.7 & 30.4 & 33.9 & 1.12 & 0.98 & 1.36 & 1.94 & 1.85 & 1.35 & 1.50 & 1.19 & 1.59 \\
\hline Apr & 23.0 & 22.5 & 26.1 & 1.44 & 1.44 & 1.63 & 1.89 & 1.77 & 1.68 & 1.35 & 1.47 & 1.65 \\
\hline May & 35.8 & $21.6^{*}$ & 25.9 & 0.98 & 1.39 & 1.32 & 1.81 & 1.62 & $0.91^{*}$ & 1.31 & 1.14 & 0.94 \\
\hline Jun & 29.7 & $17.9^{*}$ & 24.5 & 1.18 & 1.25 & 1.33 & 1.63 & 1.08 & 1.22 & 0.99 & 0.69 & 1.13 \\
\hline Jul & 23.4 & 15.6 & 14.9 & 1.12 & 1.06 & 0.96 & 1.48 & 1.05 & 1.15 & 0.95 & 0.63 & 0.91 \\
\hline Aug & 26.1 & 21.0 & 16.3 & 1.21 & 0.92 & 0.85 & 1.34 & $0.77^{*}$ & 1.00 & 1.11 & $0.54^{*}$ & $0.67^{*}$ \\
\hline Sep & 22.1 & 25.2 & 25.0 & 1.27 & 1.02 & 1.47 & 1.53 & 1.19 & 1.07 & 1.15 & 1.19 & 0.97 \\
\hline Oct & 42.4 & 44.8 & 49.9 & 0.98 & 0.65 & 0.93 & 1.74 & 1.53 & 1.48 & 1.55 & 1.25 & 1.54 \\
\hline Nov & 41.9 & 42.4 & 28.4 & 0.64 & 0.45 & 1.01 & 2.13 & 1.85 & 1.52 & 1.51 & 1.49 & 1.37 \\
\hline Dec & 29.4 & 38.7 & 37.0 & 0.76 & $0.44^{*}$ & 0.79 & 1.83 & 1.52 & 1.51 & 1.78 & 1.30 & 1.42 \\
\hline \multicolumn{13}{|c|}{ Kermanshah } \\
\hline Jan & 29.7 & 29.4 & 26.5 & 0.77 & 0.54 & 0.87 & 3.58 & $1.83^{*}$ & $1.80^{*}$ & 2.45 & 1.87 & 2.11 \\
\hline Feb & 33.3 & 24.1 & 24.1 & 1.23 & 0.87 & 1.16 & 3.48 & $1.99^{*}$ & $2.06^{*}$ & 2.54 & 1.68 & 2.16 \\
\hline Mar & 52.2 & $27.7^{*}$ & 49.2 & 1.37 & 0.92 & 1.25 & 1.84 & 1.27 & 1.65 & 1.72 & 1.63 & 1.77 \\
\hline Apr & 51.7 & 32.4 & $25.5^{*}$ & 1.18 & 1.17 & 1.10 & 1.55 & 1.37 & 1.82 & 1.48 & 1.40 & 1.96 \\
\hline May & 27.1 & 19.1 & 28.2 & 1.54 & 1.46 & 1.09 & 1.59 & 1.42 & 1.37 & 1.44 & 1.32 & 1.57 \\
\hline Jun & 2.0 & 1.7 & 1.4 & 0.95 & $0.55^{*}$ & 0.90 & 1.25 & 1.31 & 0.92 & 1.31 & 1.04 & 1.39 \\
\hline Jul & 1.3 & $2.4^{*}$ & $0.5^{*}$ & 0.87 & $0.38^{*}$ & 0.75 & 0.73 & 0.82 & 0.98 & 1.47 & 1.26 & 1.41 \\
\hline Aug & 0.9 & $0.3^{*}$ & 0.8 & 0.72 & $0.41^{*}$ & 0.79 & 1.14 & 0.90 & 0.85 & 1.32 & 0.86 & 1.04 \\
\hline Sep & 2.0 & 2.8 & 1.7 & 0.67 & 0.42 & 0.89 & 1.73 & 1.75 & $1.06^{*}$ & 1.33 & 1.30 & 1.42 \\
\hline Oct & 40.1 & 27.1 & 26.7 & 1.09 & 0.73 & 0.92 & 1.74 & 1.58 & 1.37 & 1.68 & 1.18 & 1.63 \\
\hline Nov & 62.9 & $35.4^{*}$ & 41.8 & 0.96 & $0.46^{*}$ & 1.00 & 2.00 & $1.09^{*}$ & 1.67 & 1.70 & 1.55 & 1.88 \\
\hline Dec & 34.6 & 35.6 & 36.2 & 0.71 & 0.48 & 0.80 & 1.96 & 1.69 & 2.09 & 1.71 & 1.80 & 2.37 \\
\hline
\end{tabular}
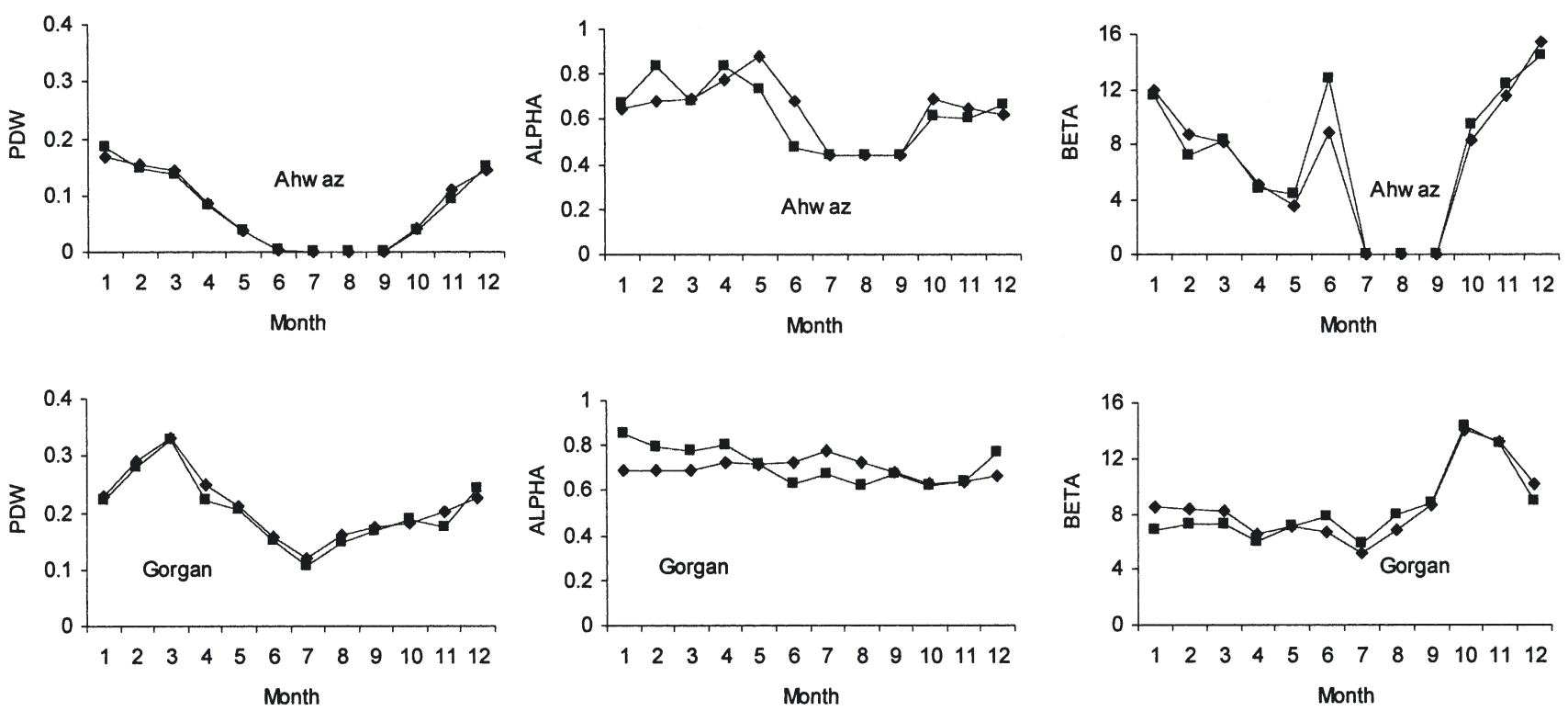

Fig. 3. Comparison of precipitation parameters estimated by SIMMETEO $(\bullet)$ with those calculated from observed data by WGEN (घ) at Gorgan and Ahwaz. The parameters are probability of a wet day following a dry day (PDW) and the $\alpha$ and $\beta$ parameters of the gamma distribution 

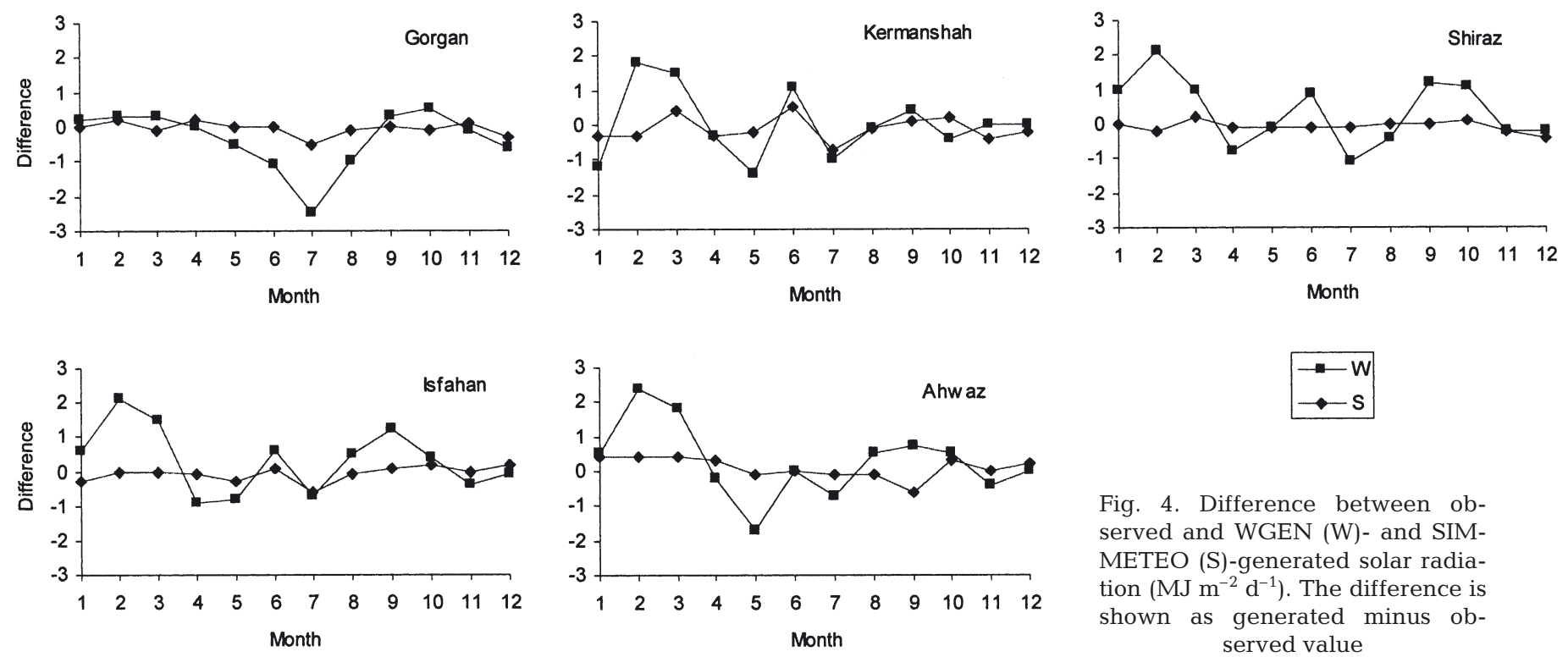

Fig. 4. Difference between observed and WGEN (W)- and SIMMETEO (S)-generated solar radiation $\left(\mathrm{MJ} \mathrm{m}^{-2} \mathrm{~d}^{-1}\right)$. The difference is shown as generated minus observed value

estimates for WGEN obtained from daily data. Examples are presented in Fig. 3 for Gorgan (with high annual precipitation) and Ahwaz (with low annual precipitation). Similar plots were observed for other locations (not shown). PDW, $\alpha$ and $\beta$ estimates for SIMMETEO were all close to those for WGEN.

\subsection{Solar radiation}

Monthly means for solar radiation generated with WGEN were significantly different from observed means in 47 to $67 \%$ of the $t$-tests (Table 3 ). SIMMETEO performed better in generating solar radiation, and the percentage of significantly different $t$-tests was $31 \%$ for Gorgan, $3 \%$ for Kermanshah, $14 \%$ for Isfahan, 25\% for Ahwaz and $3 \%$ for Shiraz. It should be noted that the significant differences found in this study for WGEN were small and generally lower than $1.5 \mathrm{MJ} \mathrm{m}^{-2} \mathrm{~d}^{-1}$ (Fig. 4). WGEN showed a tendency for over-estimation of solar radiation during January-March in 4 of the 5 selected locations (Fig. 4). Similar to the monthly averages, the variances of solar radiation generated by WGEN were significantly different from observed solar radiation in $44 \%$ of the cases across all locations (Table 4 ). However, the variances of solar radiation generated by SIMMETEO were significantly different from observed data only in Kermanshah (6\%) and Ahwaz (8\%).

An example comparison of the solar radiation parameters for WGEN and SIMMETEO is shown in Fig. 5 for Kermanshah. For other locations the results were similar and are not shown. $R_{\mathrm{D}}$ estimates of SIMMETEO obtained from monthly data were similar to those of observed data (Fig. 5). However, $R_{\mathrm{W}}$ estimates were slightly different as a result of Fourier smoothing; for the early and late months of the year, $R_{\mathrm{W}}$ estimates for SIMMETEO were lower than observed $R_{\mathrm{W}}$. Standard deviations of $R_{\mathrm{D}}$ and $R_{\mathrm{W}}$ calculated for SIMMETEO were consistently higher during middle months of the year. This occurred because SIMMETEO uses constant annual average and amplitude CV for solar radiation, which are assumed to be constant. The low percentage of significant differences between variances of observed and SIMMETEO generated solar radiation (Table 4 ) is probably a result of the over-estimation of parameter standard deviations. As mentioned previously, many stochastic weather generators, including WGEN and SIMMETEO, tend to under-predict climate variability; thus the error in parameter estimation compensated for this tendency.

Our findings contradict the results of Richardson (1981, 1985) and Richardson \& Wright (1984), who reported a good performance and only limited significant differences between monthly mean solar radiation generated by WGEN and observed mean solar radiation for conditions in the USA. However, Hansen (1999) stated that stochastic daily weather generators commonly used for biological modeling applications do not adequately reproduce the empirical distribution of global solar radiation. He showed that a modification based on a logit-transformed relative clearness was superior to the standard model that is based on a truncated Gaussian distribution. Warnock \& Puche (2001) reported that the WGEN weather generator used in DSSAT did not adequately generate year-toyear variations for solar radiation. They concluded that this discrepancy might be due to the generator's inability to generate radiation or could be attributed to the 

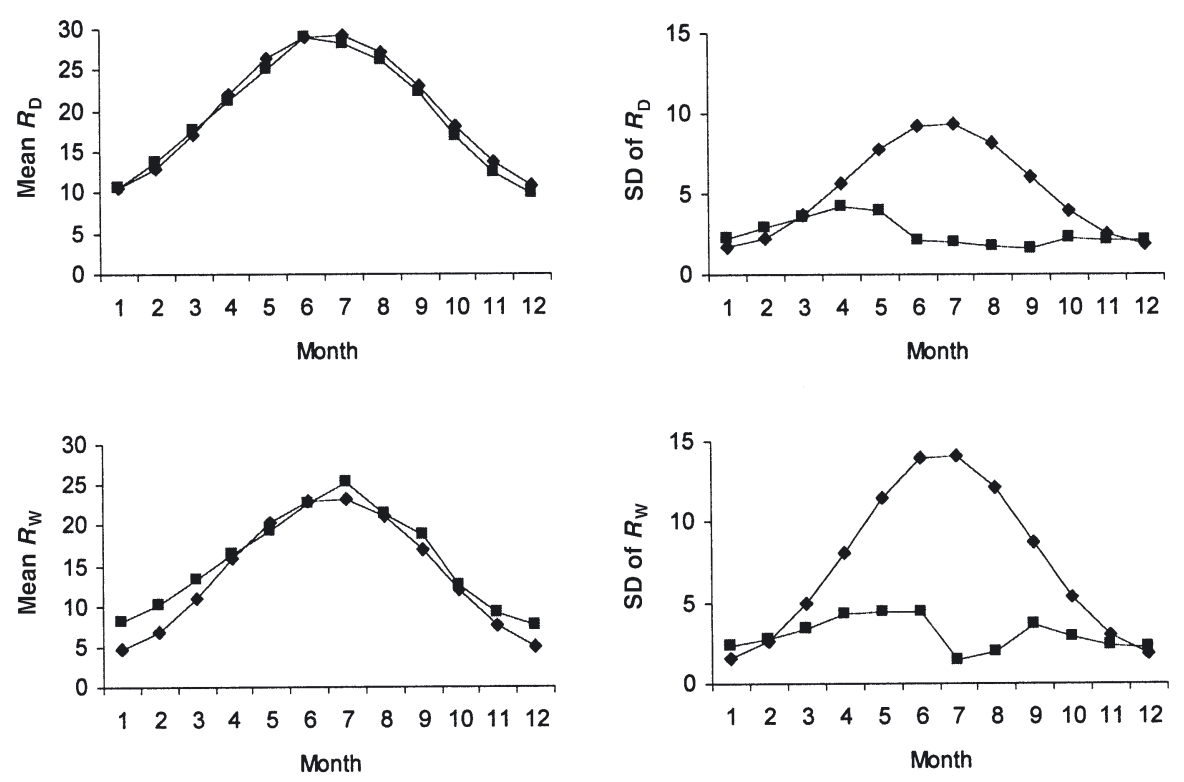

Fig. 5. Comparison of solar radiation $\left(\mathrm{MJ} \mathrm{m}^{-2} \mathrm{~d}^{-1}\right)$ parameters estimated by SIMMETEO (•) with those calculated from observed data by WGEN (ם) at Kermanshah. The parameters are means and standard deviations of solar radiation on dry $\left(R_{\mathrm{D}}\right)$ and wet $\left(R_{\mathrm{W}}\right)$ days

precipitation generator, since generated solar radiation is conditioned by the precipitation status of each day. In the present study, however, performance of the generators for mean solar radiation was independent from their performance in generating precipitation, because both generators accurately reproduced the number of wet days and total amount of precipitation.

\subsection{Maximum and minimum temperatures}

The percentage of the significant differences for the comparison of monthly means (by $t$-test) of maximum and minimum temperatures was small between the data generated with WGEN and observed data (Table 3). The performance of SIMMETEO was similar to WGEN for minimum temperature, and the percentage of significant $t$-tests varied between 0 and $8 \%$. However, for maximum temperature the performance of SIMMETEO was not as good. The percentage of $t$ tests that was rejected was greater than $28 \%$, except for Gorgan, where $17 \%$ of significant $t$-tests were detected. The monthly maximum temperatures generated by SIMMETEO were lower than observed during colder months and higher during warmer months with the maximum absolute differences between observed and generated data generally less than $1.5^{\circ} \mathrm{C}$ (Fig. 6). These differences between SIMMETEO generated and observed maximum temperature were due to smoothing the maximum temperature parameters by first-order Fourier series, as shown in Fig. 7 for Ahwaz. It seems that small differences in parameters resulted in significant differences between observed and SIMMETEO-generated maximum temperature. For mini- mum temperature, where the performance of WGEN and SIMMETEO was similar, both generators use monthly minimum temperature as an input parameter, but SIMMETEO calculates the standard deviation of the minimum temperature using a regression equation (Table 1, Eq. 13).

The variances of maximum temperature generated by WGEN were significantly different from the variances of observed data in 17 to $30 \%$ of cases, depending on the location (Table 4). For SIMMETEO this varied between 5 and $36 \%$, with the largest differences for Kermanshah and Ahwaz. The percentage of F-tests that was rejected for minimum temperature for both generators was less than $15 \%$, except for SIMMETEO for Ahwaz, which had a rejection rate of $22 \%$.

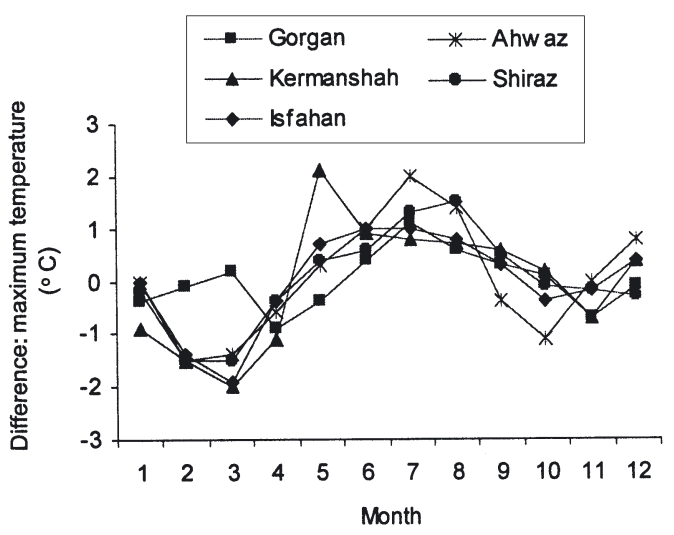

Fig. 6. Difference between observed and SIMMETEO generated maximum temperature at the selected locations. The differences are shown as generated minus observed values 

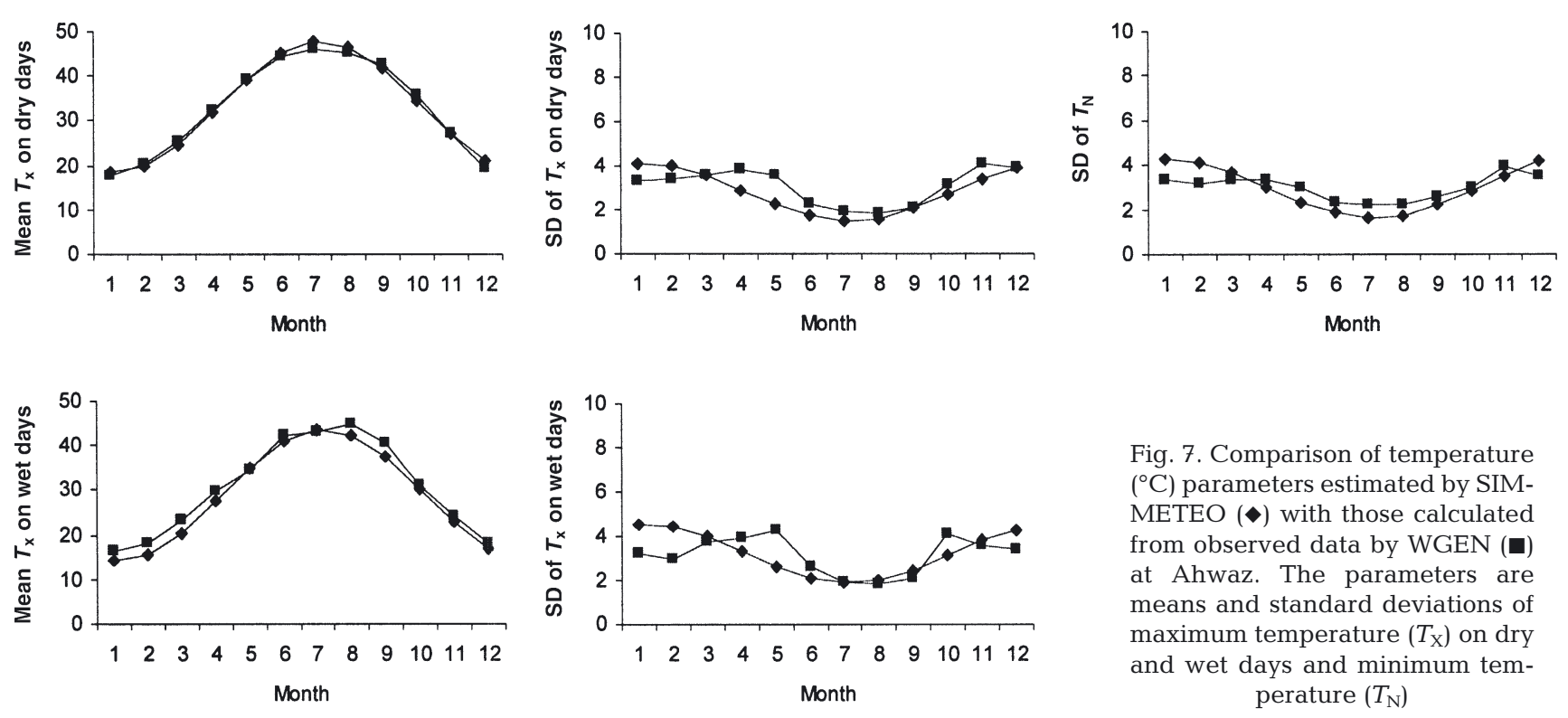

Fig. 7. Comparison of temperature
$\left({ }^{\circ} \mathrm{C}\right)$ parameters estimated by SIM-
METEO $(\bullet)$ with those calculated
from observed data by WGEN $(\mathbf{\square})$
at Ahwaz. The parameters are
means and standard deviations of
maximum temperature $\left(T_{\mathrm{X}}\right)$ on dry
and wet days and minimum tem-
perature $\left(T_{\mathrm{N}}\right)$

Thus, results showed that WGEN can adequately reproduce the central tendency and variability for maximum and minimum temperature. SIMMETEO was successful in reproducing minimum temperature with respect to central tendency and variability but less successful for maximum temperature. Similar results have also been reported by Richardson \& Wright (1984) and Hayhoe \& Stewart (1996) for WGEN. Sentelhas et al. (2001) also reported poor performance for SIMMETEO compared to WGEN in generating maximum temperature and similar performance for WGEN and SIMMETEO with respect to minimum temperature. Here, differences between the standard deviation calculated by SIMMETEO and the standard deviation calculated by WGEN (Fig. 7) did not cause a lower performance for SIMMETEO, because the percentage of significant $F$-tests was similar for both generators (Table 4).

\subsection{Temperature extremes}

One of the most potentially useful features of a weather generator is the capability to provide an indication of the extremes, which are essential for risk assessment (Hayhoe \& Stewart 1996). Extremes provide a more rigorous assessment of generator performance because they are not explicitly used in the set of the parameters of the generators. In many applications the frequency of these extremes is more important than mean values. To evaluate the generation of extreme temperature events, the number of days per month with a maximum temperature greater than $35^{\circ} \mathrm{C}$ $\left(T_{\mathrm{X}}>35\right.$, hot day) and the number of days with a mini- mum temperature less than $0^{\circ} \mathrm{C}\left(T_{\mathrm{N}}<0\right.$, frost day) were determined and compared using $t$-tests. In the comparison of average observed and WGEN-generated number of frost days, a significant difference was only found at Kermanshah (12\%), with no significant differences for the other locations (Table 3). However, WGEN did not perform well for the number of hot days; the percentage significant differences between $T_{\mathrm{X}}>35$ generated with WGEN and observed $T_{\mathrm{X}}>35$ were between 4 and $61 \%$. These significant differences were systematic and were due to the greater number of days per month with $T_{\mathrm{X}}>35$ in the generated data of WGEN (Fig. 8).

The performance of SIMMETEO was worse for generating extreme temperatures when compared to WGEN; the percentage $t$-tests comparing $T_{\mathrm{X}}>35$ that were rejected were between 19 and $67 \%$ (Table 3). For

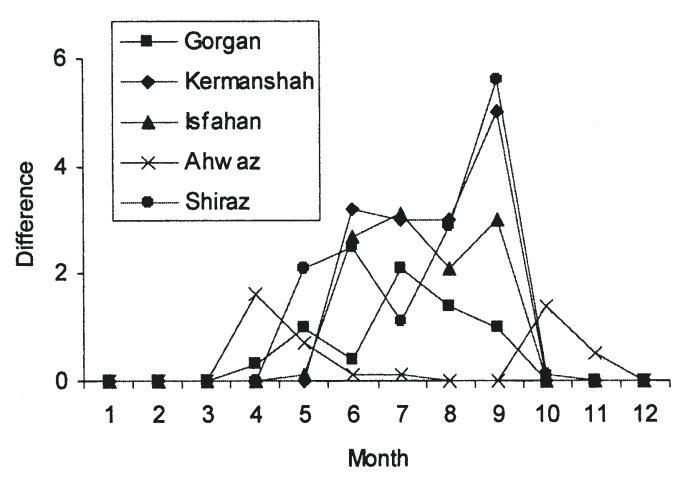

Fig. 8. Difference between observed and WGEN generated number of hot days $\left(T_{\mathrm{X}}>35\right)$. The differences are shown as generated minus observed values 

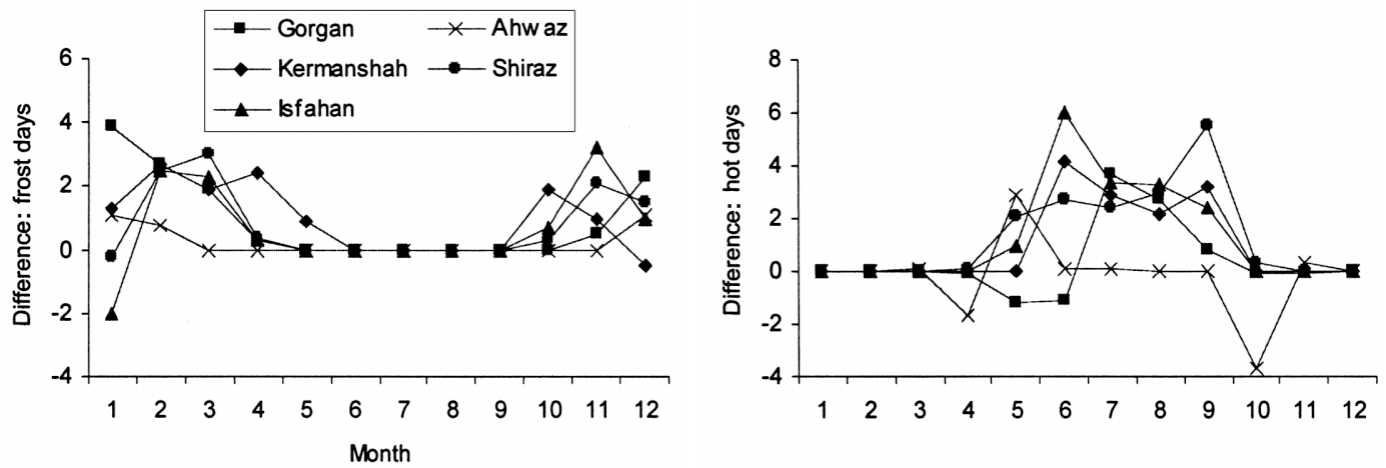

Fig. 9. Difference between observed and SIMMETEO-generated number of hot $\left(T_{\mathrm{X}}>35\right)$ and frost $\left(T_{\mathrm{N}}<0\right)$ days. The differences are shown as generated minus observed values

the number of frost days, between 27 and $61 \%$ of the $t$-tests comparing means obtained from SIMMETEOgenerated and observed data were significant. These significant differences were due to the fact that SIMMETEO generated a larger number of both hot and frost days than observed (Fig. 9). The systematic errors in the number of hot days are in the same direction as the systematic errors in maximum temperature (Fig. 6). Again, the differences between SIMMETEO and WGEN for the number of hot and frost days were due to smoothing the temperature parameters by first-order Fourier series and estimation of standard deviation by regression equations in SIMMETEO (Fig. 7).

When comparing the variance of the number of hot days, 13 to $60 \%$ of the $F$-tests for WGEN and 11 to $56 \%$ of the $F$-tests for SIMMETEO were significant (Table 4). For the number of frost days, the statistics were 0 to $36 \%$ for WGEN and 6 to $67 \%$ for SIMMETEO.

Our results showed that extremes are generally generated with less accuracy than means. The poorer performance in generating temperature extremes compared to maximum and minimum temperatures is a common characteristic observed for many generators.

Richardson (1985), Richardson \& Wright (1984), Wallis \& Griffiths (1995) and Hayhoe \& Stewart (1996) reported that the generator WGEN and a similar generator, WXGEN, did a poor job in generating realistic temperature extremes. For example, Wallis \& Griffiths (1995) reported that more than
$39 \%$ of the tests for extreme values generated with WXGEN were not within the expected range. The differences in extreme temperatures could have important implications when applied to crop models if the

Table 6. The percentage Kolmogorov-Smirnov $(\mathrm{K}-\mathrm{S})$ tests that were rejected when comparing distributions of daily data by month between observed vs generated data $(\mathrm{o}-\mathrm{g})$ and generated vs generated data $(\mathrm{g}-\mathrm{g})$. See Table 3 for definitions

\begin{tabular}{|c|c|c|c|c|c|}
\hline & & $P$ & $R$ & $T_{\mathrm{X}}$ & $T_{\mathrm{N}}$ \\
\hline \multicolumn{6}{|l|}{ Gorgan } \\
\hline \multirow[t]{2}{*}{ WGEN } & $o-g$ & 2.8 & 100.0 & 61.1 & 77.8 \\
\hline & $g-g$ & 5.6 & 0.0 & 13.9 & 19.4 \\
\hline \multirow[t]{2}{*}{ SIMMETEO } & $0-g$ & 0.0 & 47.2 & 80.6 & 88.9 \\
\hline & $g-g$ & 0.0 & 0.0 & 11.1 & 13.9 \\
\hline \multicolumn{6}{|l|}{ Kermanshah } \\
\hline \multirow[t]{2}{*}{ WGEN } & $o-g$ & 0.0 & 97.2 & 77.8 & 69.4 \\
\hline & $g-g$ & 0.0 & 2.8 & 11.1 & 19.4 \\
\hline \multirow[t]{2}{*}{ SIMMETEO } & $o-g$ & 0.0 & 5.6 & 94.4 & 97.2 \\
\hline & $g-g$ & 2.8 & 2.8 & 25.0 & 16.7 \\
\hline \multicolumn{6}{|l|}{ Isfahan } \\
\hline \multirow[t]{2}{*}{ WGEN } & $o-g$ & 0.0 & 100.0 & 66.7 & 61.1 \\
\hline & $g-g$ & 0.0 & 2.8 & 5.6 & 2.8 \\
\hline \multirow[t]{2}{*}{ SIMMETEO } & $0-g$ & 0.0 & 25.0 & 97.2 & 97.2 \\
\hline & $g-g$ & 0.0 & 8.3 & 11.1 & 16.7 \\
\hline \multicolumn{6}{|l|}{ Ahwaz } \\
\hline \multirow[t]{2}{*}{ WGEN } & $o-g$ & 0.0 & 97.2 & 61.1 & 47.2 \\
\hline & $g-g$ & 2.8 & 5.6 & 5.6 & 8.3 \\
\hline \multirow[t]{2}{*}{ SIMMETEO } & $o-g$ & 0.0 & 38.9 & 91.7 & 66.7 \\
\hline & $g-g$ & 0.0 & 2.8 & 0.0 & 13.9 \\
\hline \multicolumn{6}{|l|}{ Shiraz } \\
\hline \multirow[t]{2}{*}{ WGEN } & $o-g$ & 0.0 & 97.2 & 88.9 & 58.3 \\
\hline & $g-g$ & 2.8 & 2.8 & 13.9 & 16.7 \\
\hline \multirow[t]{2}{*}{ SIMMETEO } & $0-g$ & 0.0 & 5.6 & 91.7 & 97.2 \\
\hline & $g-g$ & 0.0 & 0.0 & 2.8 & 27.8 \\
\hline \multicolumn{6}{|c|}{ Across locations } \\
\hline \multirow[t]{2}{*}{ WGEN } & $o-g$ & 0.6 & 98.3 & 71.1 & 62.8 \\
\hline & $g-g$ & 2.2 & 2.8 & 10.0 & 13.3 \\
\hline \multirow[t]{2}{*}{ SIMMETEO } & $0-9$ & 0.0 & 24.5 & 91.1 & 89.4 \\
\hline & $g-g$ & 0.6 & 2.8 & 10.0 & 17.8 \\
\hline
\end{tabular}


differences are near the threshold values for the critical growth and development processes (Richardson 1985).

\subsection{Comparison of the distribution of daily data}

The CDFs for daily total precipitation, solar radiation, maximum and minimum temperatures from the generated and observed data were developed using the daily data of each month. The percentages of the $\mathrm{K}-\mathrm{S}$ tests for the distribution of daily data for various months that fell in the rejection region are presented in Table 6. Except for precipitation, where only small significant differences were detected, the percentage of significant $\mathrm{K}-\mathrm{S}$ tests was very high for the other variables when compared to $t$ - and F-tests. It should be noted that significant differences between distributions of monthly means of weather variables were rare (data not shown). Across locations, 98\% of the $\mathrm{K}-\mathrm{S}$ tests that compare the distribution for solar radiation, $71 \%$ of the $\mathrm{K}-\mathrm{S}$ tests that compare the distribution for maximum temperature and $63 \%$ of the $\mathrm{K}-\mathrm{S}$ tests that compare the distribution for minimum temperature generated by WGEN and observed data were rejected (Table 6). For SIMMETEO these values were $25 \%$ for solar radiation, $91 \%$ for maximum temperature and $89 \%$ for minimum temperature.

When the distribution functions of those weather variables that showed significant differences were evaluated, it was found that the significant differences are random in some cases and systematic in other cases. Because of the large number of distribution functions, it was impossible to present all of them in this paper. Therefore, some examples were selected and are shown in Fig. 10. The differences in maximum temperature at Isfahan (January) seemed to be random, but in other cases the differences were systematic. At Isfahan, when solar radiation data of January were classified into 3 groups, i.e. low (less than $10 \mathrm{MJ}$ $\left.\mathrm{m}^{-2} \mathrm{~d}^{-1}\right)$, medium (10 to $\left.15 \mathrm{MJ} \mathrm{m}^{-2} \mathrm{~d}^{-1}\right)$, and high (greater than $15 \mathrm{MJ} \mathrm{m}^{-2} \mathrm{~d}^{-1}$ ), WGEN performed adequately for the high category but tended to under-predict the low category and over-predict the medium category. For maximum temperature of July in Isfahan and Kermanshah a shift in the distribution was found towards warmer temperatures in WGEN- and SIMMETEO-generated data that resulted in a greater number of hot days, as presented in Fig. 8.

The high percentage of significant differences between distributions of generated and observed solar radiation, maximum and minimum temperatures found in this study were consistent with those reported by Meinke et al. (1995) and Sentelhas et al. (2001). In an evaluation of radiation and temperature data generators for the Australian tropics and sub-tropics, Meinke et al. (1995) showed that the distributions of WGENgenerated radiation and temperatures were generally significantly different from the observed data. Sentelhas et al. (2001) also found that the differences between distributions of observed and WGEN- and SIMMETEO-generated solar radiation and maximum and minimum temperatures were generally significant. Hayhoe (2000) also stated that the use of a simple
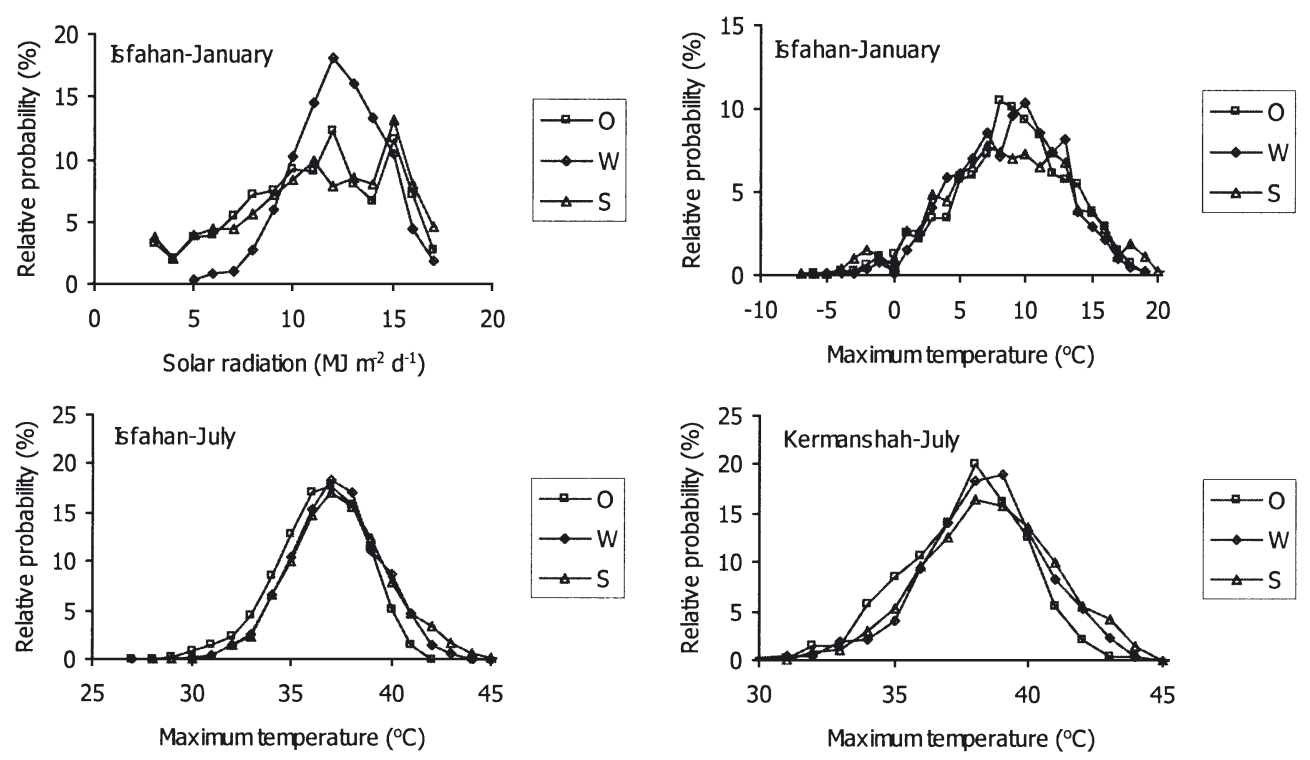

Fig. 10. Relative probability of observed (O) and WGEN (W)- and SIMMETEO (S)-generated solar radiation (Isfahan, January) and maximum temperature at Kermanshah (July) and Isfahan (January and July) 
normal distribution is inadequate in many cases and could be a cause of these differences. Semenov et al. (1998) recommended the implementation of a semiempirical distribution instead of a simple normal distribution as used here.

\subsection{Comparison of generated series}

Three weather series generated with different 'seeds' were compared using $t_{-}, F_{-}$, and $\mathrm{K}-\mathrm{S}$ tests. It should be noted that when 10 weather series were generated with different 'seeds' for Gorgan, no improvement was observed in the percentage of significant differences between the generated series. Therefore, subsequent analysis used 3 generated series for all the selected locations. The comparisons of the generated series $(g-g)$ of WGEN with $t$-test showed that between 0 and $11 \%$ of the tests were rejected, depending on the weather variable (Table 3), while for SIMMETEO between 0 and $8 \%$ of the tests were rejected. In 13 of the 35 cases (5 locations $\times 7$ weather variables) for WGEN and in 6 of the 35 cases for SIMMETEO, the percentage of significant differences between generated series was greater than $1 \%$, which was the level of probability chosen for this study. For the number of wet days and the amount of precipitation, the percentage of significant differences between generated series $(g-g)$ was greater than for the corresponding o-g comparison (Table 3 ).

The percentage of significant differences between variances of generated series $(\mathrm{g}-\mathrm{g})$ by $F$-test (Table 4 ) were generally greater than those between means conducted by $t$-test (Table 3). Across locations and weather variables, in 21 of the 35 cases for WGEN and in 23 of the 35 cases for SIMMETEO, the fraction of rejected $F$-tests was greater than $1 \%$ (Table 4 ). A greater percentage of significant differences was found between observed and generated data for the number of wet days, the amount of precipitation and the number of hot and cold events for both generators. For the number of wet days, the amount of precipitation and the number of cold events, the percentage of rejected $F$-tests in comparison with $g$-g series was comparable to that for the o-g comparison (Table 4).

The comparison of generated series $(g-g)$ for WGEN showed that $2 \%$ of the K-S tests for the amount of precipitation, $3 \%$ for solar radiation, $10 \%$ for maximum temperature and $13 \%$ for minimum temperature were in the rejected region (Table 6). For SIMMETEO these statistics were similar, with values of $1 \%$ for total precipitation, $3 \%$ for solar radiation, $10 \%$ for maximum temperature and $18 \%$ for minimum temperature. In 18 of the 20 cases for WGEN and 14 of the 20 cases for SIMMETEO, the percentage significant difference between $g-g$ series was greater than $1 \%$. Most of these significant differences were for maximum and minimum temperature (Table 6).

There are 3 probable causes for the percentage of rejected tests between generated series:

- The normal variability of weather data, which is generated by the underlying stochastic model. Hayhoe (2000) stated that since weather generators are stochastic models, some of the differences could be attributed to the normal variability of weather that would occur even if the models were a perfect representation of the real climate.

- The selection of the 'seed number' that is used to initialize the weather generators (M. A. Semenov pers. commun.). A selected 'seed' may not be very 'random' and could affect the final distributions and results of these analysis tests.

- The inappropriateness of the statistical tests or the selection of the probability level. When the probability level is $1 \%$ in the $t$-, $F$ - or $\mathrm{K}$-S-tests, it is expected that on average the null hypothesis is rejected once out of every 100 tests. When this is not the case and the tests are properly constructed, it may be concluded that these statistical tests are not appropriate for weather data comparison, or lower probability levels (say 0.001) should be chosen for such comparisons. Carmer (1976) presented arguments supporting the use of significant levels in the range of 0.2 to 0.4 (instead of conventional levels of 0.01 and 0.05 ) for the $t$-test in crop performance trials.

Further research is needed in this area. However, based on the outcomes of this study it can be stated that (1) it is not a good idea to use just 1 generated weather series, and multiple generations of daily weather data are needed; and (2) a Monte Carlo simulation study is proposed to determine the optimal significance level for statistical tests (such as $t-, F$ - and $\mathrm{K}-\mathrm{S}$ test) that are used in weather generator comparisons.

\section{CONCLUSIONS}

First, it should be noted that the algorithms used to generate weather data with both the WGEN and SIMMETEO weather generators are the same. Their main differences are due to the methods used for parameter estimation. In general, WGEN showed a good performance in reproducing the number of wet days and the total amount of precipitation, maximum and minimum temperature and the number of frost days, a moderate performance in reproducing the number of hot days and a weak performance in generating solar radiation. SIMMETEO showed a good performance in reproducing the number of wet days and the total amount of 
precipitation, solar radiation and minimum temperature, a moderate performance in generating maximum temperature and a poor job in generating extreme temperatures (the number of cold and hot days). The weak performance of SIMMETEO in generating maximum temperature and extremes temperatures compared to WGEN was related to its parameter estimation method. The main causes were the smoothing of the parameters by first-order Fourier series and using the regression equations to estimate standard deviations in SIMMETEO. It was found that small differences in parameters could lead to significant differences in generated weather compared to observed weather. The algorithms that are used for parameter estimation and/or generation of solar radiation and the number of hot days in WGEN and maximum temperature and extreme temperatures in SIMMETEO require improvement. The low variability observed for weather variables might need improvement for applications in which variability is of primary importance.

In general, the performance of WGEN and SIMMETEO for generating daily weather data was highly independent of location. Across the locations and weather variables that were evaluated, the percentage of significant differences for the comparison of means was $13 \%$ for WGEN and $19 \%$ for SIMMETEO; for the comparison of variances it was $21 \%$ for WGEN and $17 \%$ for SIMMETEO; and for the comparison of distributions it was $47 \%$ for WGEN and $43 \%$ for SIMMETEO. However, WGEN showed a better performance than SIMMETEO in generating maximum temperature and extreme temperatures, but a poorer performance in generating solar radiation. Thus, the methods used for parameter estimation (using daily weather data or monthly summaries) had relatively little effect on the quality of generated weather, especially for those variables that are used in the set of input parameters. It can be concluded that when good-quality daily weather data are available, WGEN should be preferred. However, when only monthly climate summaries are available and extremes are not of primary importance, SIMMETEO should be used and will provide a similar performance.

The comparison of generated series $(g-g)$ showed that the generated series of a weather generator based on different 'seeds' can be significantly different, probably as a result of natural variability of weather data, selection of the 'seeds' or weakness of statistical tests. Further research is needed in this area.

The generated weather series can be used in many applications, and in some of these applications the accurate generation of some variables is more important than other variables. Although some significant differences were found between observed data and data generated with WGEN and SIMMETEO based on a rigorous stringent statistical analysis at a 0.01 level of probability, the adequacy of generated data is also dependent upon the particular application. It will therefore be interesting to determine whether these differences are sufficient to cause different responses when applied to crop simulation models.

Acknowledgements. We thank F. A. Ghaderi and $\mathrm{H}$. Hajizadeh-Azad for their assistance with the statistical analysis. We also thank 3 anonymous reviewers for useful comments.

\section{LITERATURE CITED}

Bannayan M, Crout NMJ (1999) A stochastic modelling approach for real-time forecasting of winter wheat yield. Field Crops Res 62:85-95

Carmer SG (1976) Optimal significance levels for application of the least significant difference in crop performance trials. Crop Sci 16:95-99

Elliot WJ, Arnold CD (2001) Validation of the weather generator CLIGEN with precipitation data from Uganda. Trans Am Soc Agric Eng 44:53-58

Geng S, Penning de Vries FWT, Supit I (1986) A simple method for generating daily rainfall data. Agric For Meteorol 36:363-376

Geng S, Auburn JS, Brandstetter E, Li B (1988) A program to simulate meteorological variables: documentation for SIMMETEO. Agronomy Progress Rep 204, Department of Agronomy and Range Science, University of California, Davis, CA

Georgiev GA, Hoogenboom G (1999) Near real-time agricultural simulations on the web. Simulation 73:22-28

Guenni L, Charles-Edwards D, Rose R, Braddock R, Hogarth W (1991) Stochastic weather modelling: a phenomenological approach. Math Comput Simul 32:113-118

Hansen JW (1999) Stochastic daily solar irradiance for biological modeling applications. Agric For Meteorol 94:53-63

Hansen JW, Mavromatis T (2001) Correcting low-frequency variability bias in stochastic weather generators. Agric For Meteorol 109:297-310

Hartkamp AD, White JW, Hoogenboom G (2003) Comparison of three weather generators for crop modeling: a case study for subtropical environments. Agric Syst 76:539-560

Hayhoe HN (1998) Relationship between weather variables in observed and WXGEN generated data series. Agric For Meteorol 90:203-214

Hayhoe HN (2000) Improvements of stochastic weather data generators for diverse climates. Clim Res 14:75-87

Hayhoe HN, Stewart DW (1996) Evaluation of CLIGEN and WXGEN weather data generators under Canadian conditions. Can Water Resour Res J 21:53-67

Hoogenboom G (2000) Contribution of agrometeorology to the simulation of crop production and its applications. Agric For Meteorol 103:137-157

Hoogenboom G, Wilkens PW, Thornton PK, Jones JW, Hunt LA (1999) Advances in the development and application of DSSAT. In: Proc First International Symposium on Modelling Cropping Systems, 21-23 June, Lleida, Spain. Eur Soc Agron, p 201-202

Hunt LA, Kuchar L, Swanton CJ (1998) Estimation of solar radiation for use in crop modelling. Agric For Meteorol 91: 293-300

Jones PG, Thornton PK (1997) Spatial and temporal variabil- 
ity of rainfall related to a third order Markov model. Agric For Meteorol 86:127-138

Jones PG, Thornton PK (2000) MarkSim: Software to generate daily weather data for Latin America and Africa. Agron J 92:445-453

Larsen GA, Pense RB (1982) Stochastic simulation of daily climatic data for agronomic models. Agron J 74:510-514

Mavromatis T, Hansen JW (2001) Interannual variability characteristics and simulated crop response of four stochastic weather generators. Agric For Meteorol 109: 283-296

McCaskill MR (1990) TAMSIM-a program for preparing meteorological records for weather driven models. Trop Agron Tech Memo No. 65, CSIRO, Division of Tropical Crops and Pastures, Brisbane

Mearns LO, Rosenzweig C, Goldberg R (1996) The effect of changes in daily and interannual climatic variability on CERES-Wheat: a sensivity study. Clim Change 32: 257-292

Meinke H, Carberry PS, McCaskill MR, Hills MA, McLeod I (1995) Evaluation of radiation and temperature data generators in the Australian tropics and sub-tropics using crop simulation models. Agric For Meteorol 72:295-316

O'Leary GJ, Connor DJ (1998) A simulation study of wheat crop response to water supply, nitrogen nutrition, stubble retention and tillage. Aust J Agric Res 49:11-19

Pickering NB, Hansen JW, Jones JW, Wells CM, Chan VK, Godwin DC (1994) WeatherMan: a utility for managing and generating daily weather data. Agron J 86:332-337

Puche M, Silva O (2001) Assessments of generated rainfall data (EPIC) for a seasonal rainfall site. In: Proc Second International Symposium on Modelling Cropping Systems, 16-18 July, Florence, Italy. Eur Soc Agron, p 213-214

Richardson CW (1981) Stochastic simulation of daily precipitation, temperature, and solar radiation. Water Resour Res $17: 182-190$

Richardson CW (1985) Weather simulation for crop management model. Trans ASAE 28:1602-1606

Richarsdon CW, Wright DA (1984) WGEN: A model for generating daily weather variables. Agricultural Research Service, ARS-8, US Department of Agriculture, Washington, DC

Riha SJ, Wilks DS, Simons P (1996) Impact of temperature and precipitation variability on crop model predictions. Clim Change 32:293-311

SAS Institute (1989) SAS/STAT user's guide, Ver 6, 4th edn. SAS Institute, Cary, NC

Editorial responsibility: Clare Goodess,

Norwich, United Kingdom
Schubert S (1994) A weather generator bases on European 'Grosswetterlagen'. Clim Res 4:191-202

Semenov MA, Barrow EM (1997) Use of a stochastic weather generator in the development of climate change scenarios. Clim Change 35:397-414

Semenov MA, Brooks RJ, Barrow EM, Richardson CW (1998) Comparison of WGEN and LARS-WG stochastic weather generators for diverse climates. Clim Res 10:95- 107

Sentelhas PC, Faria RT, Chaves MO, Hoogenboom G (2001) Evaluation of the WGEN and SIMMETEO weather generators for the Brazilian tropics and subtropics, using crop simulation models. Braz J Agrometeorol 9:357-376

Soltani A, Latifi N, Nasiri M (2000) Evaluation of WGEN for generating long-term weather data for crop simulation. Agric For Meteorol 102:1-12

Thornton PK, Hoogenboom G (1994) A computer program to analyze single-season crop model outputs. Agron J 86: 860-868

Thornton PK, Bowen TW, Ravelo AC, Wilkens PW, Farmer G, Brock J, Brink JB (1997) Estimating millet production for famine early warning: an application of crop simulation modelling using satellite and ground-based data in Burkina Faso. Agric For Meteorol 83:95-112

Tsuji GY, Uehara G, Balas S (1994) Decision Support System for Agrotechnology Transfer, Ver 3. International Benchmark Sites Network for Agrotechnology Transfer, University of Hawaii, Honolulu

Tsuji GY, Hoogenboom G, Thornton PK (eds) (1998) Understanding options for agricultural production. Kluwer Academic Publishers in cooperation with ICASA, Dordrecht

Wallis TWR, Griffiths JF (1995) An assessment of the weather generator (WXGEN) used in the erosion/productivity impact calculator (EPIC). Agric For Meteorol 73:115-133

Warnock R, Puche M (2001) Assessing generated weather data to explore management scenarios in Venezuela. In: Proc Second International Symposium on Modelling Cropping Systems, 16-18 July, Florence, Italy. Eur Soc Agron, p 255-256

Wilks DS (1992) Adapting stochastic weather generation algorithms for climate change studies. Clim Change 22: 67-84

Wilks DS (1999) Interannual variability and extreme-value characteristics of several daily precipitation models. Agric For Meteorol 93:153-169

Wilks DS, Wilby RL (1999) The weather generation game: a review of stochastic weather models. Prog Physic Geogr 23:329-357

Submitted: November 15, 2002; Accepted: June 3, 2003

Proofs received from author(s): August 12, 2003 